\title{
Resenha: Habilidades Sociais, Desenvolvimento e Aprendizagem: Questões Conceituais, Avaliação e Intervenção
}

\author{
Maria Rita Zoéga Soares ${ }^{1}$ \\ Universidade Estadual de Londrina
}

\section{Book Review: Social Skills, Development and Learning: Conceptual Issues, Evaluation and Intervention}

A presente publicação trata do tema do desenvolvimento e das relações interpessoais, resultado do encontro e discussão do grupo Relações Interpessoais e Competência Social realizado na reunião da Associação Nacional de Pesquisadores em Psicologia (ANPEPP) em 2002. A obra reúne pesquisadores de diversas instituições de ensino superior e apresenta questões que se integram e se complementam acerca do tema proposto, permitindo a ampliação do conhecimento e a atualização de referências. Contém estudos teóricos e relatos sistematizados de pesquisa empírica, demonstrando preocupação com a análise de instrumentos e procedimentos de avaliação. Apresenta propostas viáveis de procedimentos de intervenção para a promoção de habilidades sociais em diferentes contextos.

Gomide compila e analisa a literatura sobre estilos parentais e sua relação com o comportamento social da criança em desenvolvimento. Parte, inicialmente, de uma apresentação sobre o comportamento anti-social e os critérios mais utilizados para sua definição. Em seguida, apresenta resultados de pesquisas sobre as principais categorias descritivas de práticas educativas positivas e negativas no desenvolvimento social da criança. Finaliza com a descrição de um inventário, produzido pela autora, de estilos parentais e identificação de famílias de risco.

O comportamento anti-social infantil (questões teóricas e de pesquisa) é analisado por Marinho através de uma extensa revisão bibliográfica sobre a área, identificando seus principais determinantes no desenvolvimento infantil. A autora apresenta a produção do grupo de pesquisa do Oregon Social Learning Center, que vem obtendo resultados relevantes sobre questões relacionadas ao comportamento anti-social da criança. Finaliza fornecendo sugestões para a prevenção de comportamento anti-social e para a identificação de variáveis a serem focalizadas em pesquisas futuras.

Del Prette e Del Prette enfocam a aprendizagem socioemocional na infância e a prevenção da violência relacionando-as com questões conceituais e metodologias de intervenção. $\mathrm{O}$ capítulo apresenta uma revisão de estudos sobre a violência, incluindo pesquisas com crianças no contexto escolar. Identificam o fenômeno da violência como foco de estudo de diversas disciplinas científicas sob diferentes perspectivas teóricas, integrando os vários modelos de análise.

1 Endereço: Universidade Estadual de Londrina, Departamento de Psicologia Geral e Análise do Comportamento, Rodovia Celso Garcia Cid km 380, Caixa Postal 6001, Londrina, PR, Brasil 86051-990. E-mail: mrzoega@sercomtel.com.br
Consideram a violência como parte integrante de uma cultura de agressividade que permeia instituições como a família e a escola. Discutem a necessidade de utilizar a prevenção como alternativa para lidar com tal fenômeno e examinam dados advindos de pesquisas sobre alternativas metodológicas disponíveis para o enfrentamento do problema. Sugerem a utilização do método vivencial como um recurso para implementar o desenvolvimento socioemocional e para a promoção de habilidades sociais e cognitivas da criança.

Carneiro analisa o conceito de inteligência como capacidade cognitiva e acadêmica, relacionando-o com o conceito de competência, ou seja, discute a inteligência e a competência social. A autora apresenta, com muito critério, diferentes teorias sobre a inteligência, integrando-as com modelos de competência. Apresenta conceitos relacionados à adaptação, competência social e habilidades sociais. Finaliza discutindo a relação, complexa e recíproca, entre fatores cognitivos e comportamentais em termos de competência social.

Falcone aborda a importância das habilidades sociais do terapeuta cognitivo-comportamental na interação com pacientes difíceis, respaldando-se em pesquisas sobre a qualidade da relação terapêutica como fator determinante da eficácia do tratamento e enfocando as habilidades sociais presentes no contexto terapêutico. A autora considera a empatia como condição fundamental, mas insuficiente, para a condução eficaz do processo psicoterápico, sendo necessário o desenvolvimento de outras habilidades. Aborda, também, problemas no atendimento relacionados a variáveis do cliente e também do terapeuta, ressaltando como condição relevante, a forma como o profissional introduz seus procedimentos na terapia.

Em outro capítulo, Del Prette e Del Prette analisam as habilidades sociais relacionando-as com as dificuldades de aprendizagem. São apresentadas questões teóricas e metodológicas, além de uma revisão de pesquisas na área. Com base em uma abordagem multimodal de avaliação de habilidades sociais, apresentam um estudo empírico sobre o desempenho social de crianças escolares com e sem dificuldade de aprendizagem. Discutem, finalmente, as implicações práticas dos resultados e propõem encaminhamentos para reflexão e futuras pesquisas.

O treinamento de habilidades sociais de crianças agressivas, em grupo, associado à orientação dos pais, é abordado por Baraldi e Silvares, através da análise empírica de uma proposta de atendimento. As autoras realizam revisão de literatura sobre a terapia comportamental e a agressão infantil, ressaltando o modelo de Patterson para a compreensão do 
comportamento anti-social. Apresentam evidências a favor do atendimento infantil aliado ao treinamento simultâneo dos pais. Descrevem os resultados obtidos através de uma intervenção que inclui um programa de atendimento aos pais. Para a avaliação, utilizam a aplicação do Children Behavior Check List e gravações de áudio e vídeo. A análise dos resultados é feita com base na literatura, sugerindo encaminhamentos para atendimento e pesquisa.

Marturano e Loureiro abordam o desenvolvimento socioemocional e as queixas escolares a partir de uma concepção de desenvolvimento, onde enfatizam o comportamento como resultado de experiências externas e como função de variáveis internas do indivíduo. Através do levantamento bibliográfico, analisam o desenvolvimento e a aprendizagem infantil, destacando fatores internos e externos presentes na escolaridade. Apresentam estudos sobre temas relacionados a autopercepção, autoconceito e autoeficácia, relacionando-os ao desempenho escolar, à aceitação ou à rejeição por pares e aos problemas de comportamento e a saúde. Realizam comparações entre os resultados de pesquisa conduzidas em nosso meio e indicam sugestões para estudos posteriores.

A estimulação do desenvolvimento de habilidades sociais em idade escolar é abordada por Löhr através do relato de sua experiência de trabalho desenvolvida junto a Universidade Federal do Paraná. Apresenta um levantamento bibliográfico sobre programas de intervenção com crianças. Descreve resumidamente um programa desenvolvido pela equipe da universidade, direcionado a um grupo de crianças e que integra o atendimento dos pais. Finaliza com considerações pertinentes, apontando as dificuldades encontradas para a condução de pesquisas nessa área.

A obra, além de discutir as relações interpessoais e a competência social, busca sugerir o desenvolvimento de pesquisas que venham a contribuir para a intervenção nessa importante área da Psicologia. Da análise de todo este conteúdo, pela articulação dos diferentes temas, pode-se deduzir a importância desse trabalho para a Psicologia, a Pedagogia, a Educação, as Ciências Sociais e afins, que tanto se preocupam com a questão das relações humanas.

\section{Referência}

Del Prette, A. \& Del Prette, Z. (Orgs.). (2003). Habilidades sociais, desenvolvimento e aprendizagem: Questões conceituais, avaliação e intervenção. Campinas, SP: Alínea. 